\title{
CLASSROOM ASSESMEN PADA ASPEK PERKEMBANGAN NILAI AGAMA DAN MORAL DI TKIT AL-IKHLAS AL-MA'ARIF CIREBON
}

\author{
AIP SARIPUDIN \\ Pendidikan Islam Anak Usia Dini IAIN Syekh Nurjati Cirebon \\ Email: doubleaip82@gmail.com \\ TIARA ANING AWELAS \\ Pendidikan Islam Anak Usia Dini IAIN Syekh Nurjati Cirebon \\ Email: tiaraaning7@gmail.com
}

Article received: 13 Juli 2020, Review process: 21 September 2020,

Article Accepted: 28 September 2020, Article published: 30 September 2020

\begin{abstract}
Assessment activities is a piece of learning which could not be separated with early childhood learning .Assessment presents on every learning session practicing by teachers or parent. Assessment development activities on various aspects allow teachers and parent knowing the growth of early childhood that would give stimulation if there was an advanced ability been attained. Also with value of religion and moral, teachers and parents in TKIT Al-Ikhlas AlMaarif always do the assessment collaboration. Teachers in TKIT Al-Ikhlas Al-Maarif had also tried to stimulate in developing the students capability, religion and moral. So, the children who have not fulfilled these assessment could be stimulated as early as possible. The methods used in this research was using the data through qualitative observation and interview. The Observation was doing when the learning activities, while the interview directed to the teachers TKIT Al-Iklash Al-Maarif. Assessment value of the moral and religious was made over two months, then the researcher discovered that the average of 10 children had developed as expected. This could be seen from some indicators of the moral and religious value which are accomplished. This research is appropriate with a Standar Tingkat Pencapaian Perkembangan Anak (STPPA) with percentage excellent (86,7 \%).
\end{abstract}

Keyword: Assesmen, value of religion and moral, PAUD

\begin{abstract}
Abstrak
Kegiatan asesmen merupakan salah satu bagian yang tidak bisa dipisahkan dari proses pembelajaran anak usia dini. Asesmen senantiasa hadir pada setiap sesi pembelajaran anak baik dilakukan oleh guru maupun dilakukan oleh orang tua. Kegiatan asesmen dalam berbagai aspek perkembangan memungkinkan guru dan orangtua mengetahui perkembangan dan
\end{abstract}


pertumbuhan anak secara dini, sehingga dapat memberikan stimulasi lanjutan apabila terdapat kemampuan anak yang belum tercapai. Begitupula dengan perkembangan Nilai Agama dan Moral, guru dan orang tua di TKIT Al-Iklash Al-Maarif senantiasa berkolaborasi dalam melakukan asesmen. Guru di TKIT AL-Ikhlas Al-Ma'arif juga telah melakukan upaya stimulasi dalam mengembangkan nilai agama dan moral peserta didik, sehingga anak yang belum memenuhi capaian perkembangan dapat sedini mungkin distimulasi. Adapun metode yang digunakan dalam penelitian ini yakni menggunakan metode kualitatif dengan data yang diperoleh melalui observasi dan wawancara. Observasi dilakukan di sekolah selama kegiatan pembelajaran berlangsung, sementara wawancara dilakukan kepada guru kelas A TKIT Alikhlas Al-Maarif. Hasil asesmen perkembangan nilai moral dan agama yang dilakukan dalam kurun waktu dua bulan, maka peneliti menemukan fakta bahwa dari 10 anak yang diteliti ratarata dapat dikatakan sudah berkembang sesuai harapan. Hal ini terlihat dari beberapa indikator Nilai Moral dan Agama sudah mampu tercapai. Hal ini sesuai dengan Standar Tingkat Pencapaian Perkembangan Anak (STPPA) dengan nilai presentase sangat baik $(86,7 \%)$.

Kata Kunci: Asesmen, Perkembangan nilai moral dan agama, PAUD

\section{PENDAHULUAN}

Anak usia dini menurut UNESCO adalah anak yang berada pada rentang usia 0-8 tahun sedangkan di Indonesia yang dimaksud anak usia dini yaitu anak yang berada pada rentang usia 0-6 tahun. Pada masa ini anak berada pada masa emas atau yang biasa disebut dengan golden age, dimana anak anak mengalami masa perkembangan dan pertumbuhan yang sangat pesat. Anak usia dini juga sering disebut dengan anak yang unik, berbeda dan memiliki kemampuan yang tidak terbatas.

Menurut white dan Bloom menyatakan bahwa perkembangan anak usia 0-4 tahun bisa mencapai 50\% sedangkan pada usia 8 tahun mencapai $80 \%$ dan usia 8 tahun ketas mencapai $20 \%$ (Talango \& Pratiwi, 2018). Oleh karena itu, pada rentang usia tersebut anak berada pada periode kritis dan sensitif sehingga sudah seharusnya guru ataupun orang tua untuk mengembangkan seluruh aspek perkembangan pada anak. Selain itu, perlunya anak distumulasi dengan cara yang tepat sesuai dengan usia dan minat anak. Mengingat sangat pentingnya perkembangan pada anak usia dini, perlu juga dilakukan asesmen perkembangan yang memang bagian penting yang tidak bisa dipisahkan dalam perkembangan anak usia dini.

Asesmen perkembangan adalah proses dalam mengumpulkan, menyatukan dan menginterpretasikan informasi mengenai perkembangan dan belajar anak usia dini. Asesmen perkembangan yang dibuat guru harus dapat menggambarkan perkembangan anak secara menyeluruh, sehingga bermanfaat dalam membuat keputusan tentang penyusunan kebutuhan 
AWLADY: Jurnal Pendidikan Anak

Homepage: www.syekhnurjati.ac.id/jurnal/index.php/awlady

Email : pgrasyekhnurjati@gmail.com

P-ISSN: 2541-4658

E-ISSN: 2528-7427

dan program yang tepat untuk membantu anak agar berkembang secara maksimal (Hartati, 2017).

Tujuan asesmen perkembangan yang dilakukan pada Pendidikan anak usia dini diantaranya adalah (1) untuk mengidentifikasi minat dan kebutuhan anak. (2) untuk mendeteksi seluruh aspek perkembangan anak. (3) menggambarkan kemajuan perkembangan dan pembelajaran anak. (4) mengembangan kurikulum. (5) memperbaiki dan memajukan pembelajaran agar sesuai dengan kemajuan dan kebutuhan anak. (6) mengasesmen lembaga (suyadi, 2016).

Perkembangan nilai agama dan moral merupakan kemampuan anak untuk bersikap dan bertingah laku sesuai dengan norma-norma agama yang dianut. Semua agama tentunya telah mengajarkan nilai-nilai positif yang bermanfaat dalam kehidupan berbangsa dan bernegara. Hal ini menyebabkan perlunya pengembangan pembelajaran terkait nilai nilai moral dan agama. Orang tua dan guru memiliki peran yang sangat penting dalam mengembangkan nilai agama dan moral anak. Peran-peran orangtua dalam mengembangkan nilai moral dan agama dilakukan di lingkungan keluarga. Sedangkan peran guru yakni menstimulasi NAM dalam lingkungan sekolah.

Lingkungan keluarga merupakan lembaga pendidikan yang utama dan pertama dalam mengembangkan karakter positif anak. Keluarga tidak hanya sekedar berfungsi sebagai persekutuan sosial, tetapi juga merupakan lembaga pendidikan yang sangat penting keberadaannya. oleh sebab itu kedua orang tua bahkan semua orang dewasa berkewajiban membantu, merawat, membimbing dan mengarahkan anak-anak yang belum dewasa di lingkungannya dalam pertumbuhan dan perkembangan mencapai kedewasaan masing-masing dan dapat membentuk kepribadian, karena pada masa usia dini adalah masa peletakan dasar pertama dalam mengembangkan kemampuan fisik, moral dan agama.

Kegiatan asesmen yang dilakukan di kelompok A TKIT Al-Ikhlas Al-Ma'arif difokuskan pada aspek perkembangan Nilai Agama dan Moral (NAM). Dimana proses asesmen perkembangan NAM dilakukan dengan menciptakan suasana pembelajaran yang menyenangkan dan apa adanya agar proses asesmen berjalan dengan sebenar-benarnya sesuai dengan kemampuan anak. Berdasarkan hal tersebut diatas, maka penelitian ini bertujuan untuk mengetahui sejauh mana perkembangan anak usia dini dilihat dari aspek perkembangan nilai 
AWLADY: Jurnal Pendidikan Anak

Homepage: www.syekhnurjati.ac.id/jurnal/index.php/awlady

Email : pgrasyekhnurjati@gmail.com

P-ISSN: 2541-4658

E-ISSN: 2528-7427
Vol. 6, No. 2, September 2020

316

moral dan agama berdasarkan iindikator yang telah ditentukan. Data yang diperoleh selanjutnya dijadikan bahan evaluasi dalam memberikan stimulasi lanjutan yang dilakukan oleh guru maupun orang tua.

\section{METODOLOGI}

Pendekatan dalam penelitian ini menggunakan pendekatan kualitatif deskriptif. Data yang diperoleh melalui observasi dengan menggunakan instrumen yang dikembangakan dari indikator aspek nilai agama dan moral. Adapun indikator aspek nilai moral dan agam meliputi (1) Anak mampu bersalaman dengan guru, (2) Anak mampu mengucap salam, (3) Anak mampu meminta maaf, (4) anak mampu menolong temannya, (5) Anak mampu mengucap kata tolong, (6) Anak mampu menjawab salam, (7) Anak mampu berbicara dengan sopan, (8) Anak mampu mengucapkan kata terimakasih, (9) Anak mampu mengacungkan tangan, (10) Anak mampu mentaati perintah guru. Kegiatan penelitian dilakukan pada Oktober 2019 di TKIT AL-ikhlas Al-Ma'arif Kab Cirebon Jawa Barat. Selain menggunakan observasi, juga menggunakan teknik wawancara dalam pengambilan data terkait dengan aspek nilai moral dan agama. Wawancara dilakukan kepada guru dan orangtua peserta didik. Teknik analisis data menggunakan analisis deskriptif prsesntase dengan perhitungan ketuntasan individu. Hasil data lapangan kemudian di anaslisis secara mendalam menggunakan teori-teori yang relevan dengan aspek-aspek perkembangan yang diteliti.

\section{HASIL DAN PEMBAHASAN}

Menurut Piaget menyatakan bahwa perkembangan moral terjadi dalam dua tahapan yang jelas. Anak usia prasekolah berada pada tahap pertama yaitu realisme moral. Pada tahap ini anak menganggap bahwa orang tua dan orang yang dewasa berhak dan membuat aturan, lalu mereka harus mengikuti peraturan yang dibuaat atau diberikan tersebut tanpa mengerti apa maksud dari peraturan tersebut. Misalnya anak akan menganggap suatu hal itu salah jika mendapat hukuman dari orang tua atau guru (Anggraini \& Syafril, 2018).

Pada asesmen perkembangan NAM, menggunaka sepuluh instrumen sebagai berikut: (1) Anak mampu bersalaman dengan guru, (2) Anak mampu mengucap salam, (3) Anak mampu meminta maaf, (4) anak mampu menolong temannya, (5) Anak mampu mengucap kata tolong, (6) Anak mampu menjawab salam, (7) Anak mampu berbicara dengan sopan, (8) 
AWLADY: Jurnal Pendidikan Anak

Homepage: www.syekhnurjati.ac.id/jurnal/index.php/awlady

Email : pgrasyekhnurjati@gmail.com

P-ISSN: 2541-4658

E-ISSN: 2528-7427
Vol. 6, No. 2, September 2020

Anak mampu mengucapkan kata terimakasih, (9) Anak mampu mengacungkan tangan, (10) Anak mampu mentaati perintah guru.

Hasil asesmen perkembangan nilai agama dan moral secara keseluruhan nilai rata-rata klasikal memperoleh kemampuan sebesar $61,8 \%$. Secara klasikal siswa TKIT Al-Ikhlas AlMaarif berkategori berkembang sesuai harapan. Namun jika hasil asesmen dilihat secara individual siswa TKIT memiliki kemampuan yang berbeda satu dengan yang lainnya. Hal ini tercermin dari perolehan nilai asesmen pada setiap kategori yang beragam.

Hasil asesmen perkembangan nilai agama dan moral atas nama AQ mendapatkan hasil presentase pencapaian keberhasilan sebesar 55\% dengan kategori Berkembang Sesuai Harapan (BSH). Hal ini dapat dilihat dari asesmen hari pertama AQ dapat menolong temannya untuk mencari penghapus yang hilang dan termasuk dalam instrumen item keempat. Lalu yang kedua adalah FT dengan perolehan presentase pencapaian keberhasilannya 55\% dengan kategori Berkembang Sesuai Harapan (BSH). hal ini terlihat pada instrumen item ketiga, dimana saat berkelahi dengan temannya ia meminta maaf walaupun memang diingatkan oleh gurunya.

Selanjutnya GMR mendapatkan hasil presentase pencapaian keberhasilan sebesar 62,5\% dengan kategori kembang Sesuai Harapan (BSH). Dimana terlihat pada item ketiga GMR seperti sudah terbiasa dalam mengucapkan salam saat masuk dan pulang sekolah. Selanjutnya yang keempat adalah MPR dengan presentase pencapaian keberhasilan sebesar 70\% dengan kategori Berkembang Sesuai Harapan (BSH). terlihat pada saat ingin mengambil mainan yang tinggi galang meminta tolong pada gurunya dimana termasuk dalam item kelima. Kelima adalah NF dengan presentase pencapaian keberhasilan sebesar 52,5\% dengan kategori Berkembang Sesuai Harapan (BSH). terlihat dari item kelima NF meminta tolong gurunya untuk mencarikan penghapus Aqilla yang hilang.

Selanjutnya adalah PW dengan perolehan presentase pencapaian keberhasilan sebesar 62,5\% dengan kategori Berkembang Sesuai Harapan (BSH). Terlihat dalam item kedua PW mendapatkan nilai berkembang sangat baik, karena saat masuk kelas Pandu mengucap salam dengan spontan. Selanjutnya DI dengan mendapatkan hasil presentase pencapaian keberhasilan sebesar 55\% dengan kategori Berkembang Sesuai Harapan (BSH). terlihat saat DI membantu gurunya yang sedang membereskan meja DI ikut membantu. 
AWLADY: Jurnal Pendidikan Anak

Homepage: www.syekhnurjati.ac.id/jurnal/index.php/awlady

Email : pgrasyekhnurjati@gmail.com

P-ISSN: 2541-4658

E-ISSN: 2528-7427
Vol. 6, No. 2, September 2020

318

Lalu ada RA dengan presentase pencapaian keberhasilan sebesar 72,5\% dengan kategori Berkembang Sesuai Harapan (BSH). Raka pada hari pertaman dan kedua mengucap salam dengan spontan dan sambil tersenyum dan bersalaman dan termasuk pada item kesatu. Kemudian SL dengan presentase pencapaian keberhasilan sebesar 70\% dengan kategori Berkembang Sesuai Harapan (BSH). Sama seperti RA, SL berkembang sangat baik pada item kesatu terlihat saat masuk kelas spontan mengucap salam. Terakhir ada HY dengan presentase pencapaian keberhasilan sebesar 65\% dengan kategori Berkembang Sesuai Harapan (BSH), yang terlihat pada item kepuluh terlihat setiap ada pertanyaan dari guru HY mengacungkan tangan terlibih dahulu saat ingin menjawab.

Mengacu pada deskripsi hasil asesmen perkembangan pada aspek nilai moral dan agama, maka dapat disajikan pula dalam bentuk diagram. Berikut adalah lebih lengkap presentase seluruh anak dalam bentuk diagram :

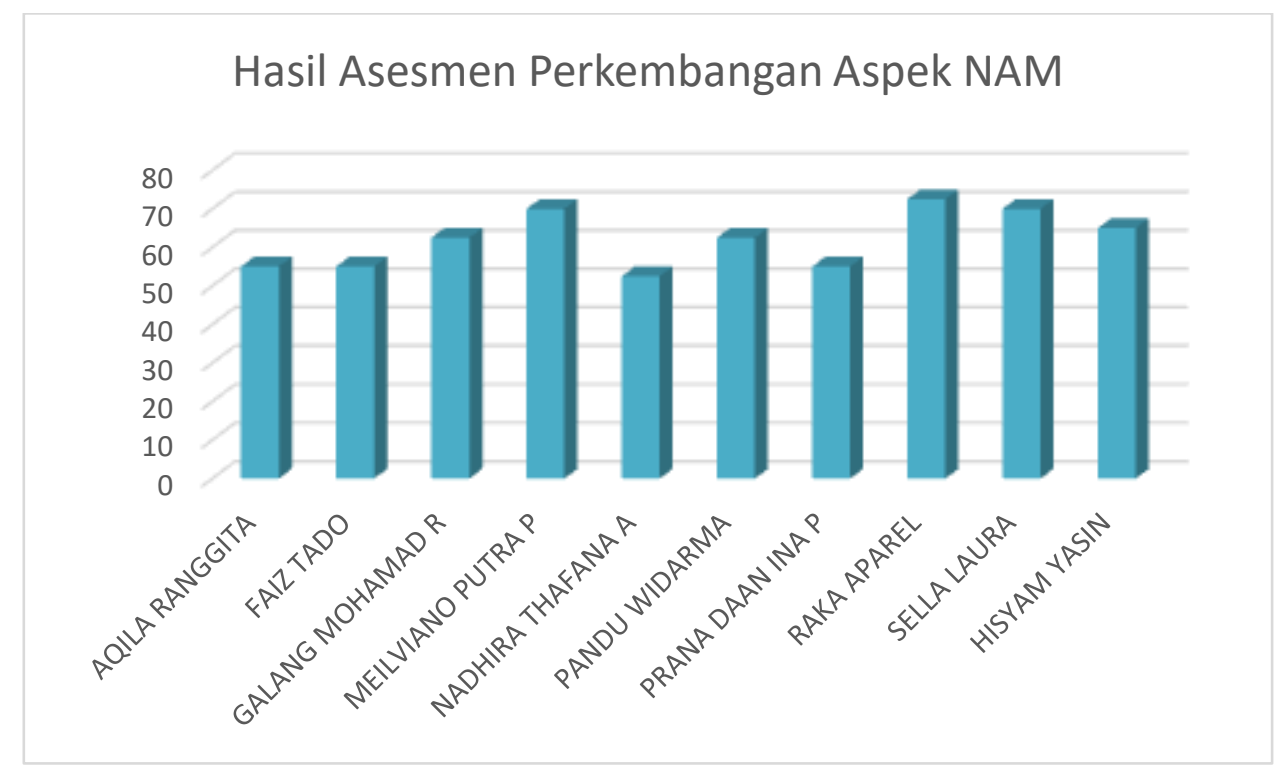

(Diagram 3 Hasil Asesmen Perkemabangan Aspek Perkembangan NAM)

Perkembangan Nilai agama dan moral merupakan suatu kemampuan untuk berinteraksi dengan tingkah laku yang baik atau buruk sesuai dengan norma-norma, sehingga menimbulkan perilaku yang baik dan buruk (Anggraini \& Syafril, 2018). Sedangkan yang dimaksud moral keagamaan adalah perkembangan moral dan agama anak prasekolah adalah suatu kemampuan untuk berinteraksi dengan tingkah laku yang baik atau buruk sesuai dengan 
AWLADY: Jurnal Pendidikan Anak

Homepage: www.syekhnurjati.ac.id/jurnal/index.php/awlady

Email : pgrasyekhnurjati@gmail.com

P-ISSN: 2541-4658

E-ISSN: 2528-7427
Vol. 6, No. 2, September 2020

norma-norma, sehingga menimbulakn perilaku yang baik dan buruk (Anggraini \& Syafril, 2018).

Menurut J.Bull perkembangan moral anak dibagi menjadi tiga yaitu, tahap anomi atau tahap ketidak mampuan moral bayi. Pada tahap ini mral bayi barulah suatu potensi yang siap dikembangkan dalam lingkungan. Tahap kedua yaitu heteronomi, dimana moral berpotensi berkembang dari orang lain atau otoritas melalui aturan dan kedisiplinan. Tahap yang ketiga yaitu tahap sosionomi, yaitu dimana moral berkembang ditengah masyarakat dan lebih mentaati aturan kelompok. Setelah itu ada juga tahap otonomi, yaitu moral yang mengisi dan mengendalikan kata hati seta kemampuan bebasnya untuk berperilaku tanpa tekanan dari lingkungan (Laila Maharani, 2014).

Berdasarkan dari hasil asesmen perkembangan NAM yang dilakukan oleh peneliti kepada sepuluh anak tersebut diperoleh hasil 100\% yang berkategori Berkembang Sesuai Harapan (BSH). Hal ini menunjukkan bahwa dari kesepuluh anak tersebut memperoleh nilai dengan kategori Berkembang Sesuai Harapan (BSH) dengan rentang presentase capaian keberhasilannya yaitu pada kisaran 52,5-72,5\% dan tidak ada masalah dalam perkembangannya. Berdasarkan capaian tersebut dapat kira lihat dari salah satu anak yang bernama SL dan RA.

Misalnya SL dan RA adalah anak yang mendapat nilai Berkembang Sangat Baik (BSB) dalam instrumen pertama yaitu dengan indikator mampu bersalaman dengan guru. Kedua anak tersebut terlihat sudah terbiasa bersalaman saat masuk dan pulang, bahkan peneliti melihat kedua anak tersebut bersalaman sambil mengucap salam. Hal ini menggambarkan bahwa anak sudah berkembang dengan baik dan sesuai dengan Standar Tingkat Pencapaian Perkembangan Anak (STPPA) yang tercantum dalam Permendikbud Nomor 137 tahun 2014.

Tercantum dalam Permendikbud Nomor 137 tahun 2014 yang berisi bahwa anak usia 4-5 tahun sudah mengenal perilaku baik atau sopan dan buruk, membiasakan diri berperilaku baik dan mampu mengucap salam dan menjawab salam. Dari penjelasan tersebut bisa dikatakan bahwa pada perkembangan aspek NAM pada kelompok A TKIT AL-Ikhlas AlMa'arif sudah berkembang dengan baik. 
AWLADY: Jurnal Pendidikan Anak

Homepage: www.syekhnurjati.ac.id/jurnal/index.php/awlady

Email : pgrasyekhnurjati@gmail.com

P-ISSN: 2541-4658

E-ISSN: 2528-7427
Vol. 6, No. 2, September 2020

Selain itu dari hasil wawancara dengan guru yang mengajar di kelas tersebut mengungkapkan bahwa memang hampir semua anak yang diasesmen dalam penelitian ini sudah berkembang dalam indikator yang menjadi bahan asesmen. Namun terkadang anakanak melakukan hal itu tidak bersifat permanen atau dengan kesadaran penuh. Contohnya pada saat anak berkelahi dengan temannya yang bernama FZ, anak tersebut tidak mau meminta maaf, namun saat guru mengatakan bahwa itu adalah hal yang salah anak tersebut lalu meminta maaf. Hal itu menunjukkan bahwa anak sebenarnya tidak begitu paham arti dari meminta maaf, namun karena memang menurut gurunya salah dan harus meminta maaf maka anak tersebut meminta maaf tanpa mengetahui makna yang sebenarnya. Hal ini sejalan dengan apa yang dikatakan Kohlberg.

Menurut teori yang dikemukakan oleh Kohlberg yang menyatakan bahwa perkembangan moral anak pra sekolah berada pada tingkatan yang paling dasar yang dinamakan dengan penalaran prakonvensional. Pada tingkatan ini anak belum menunjukkan internalisasi nilai-nilai moral secara kokoh. Namun pada usia ini anak memiliki kepekaan yang tinggi dalam merespons yang baik atau buruk. Pada tahap ini pula anak melihat suatu kegiatan benar atau salah berdasarkan hukuman dan kepatuhan. Misalnya suatu kegiatan yang membuat ibu marah maka itu adalah tindakan yang salah.

Guru tersebut juga mengungkapkan bahwa jika memang kebiasaan-kebiasaan baik tersebut dibiasakan, maka akan tumbuh di diri anak dengan kokoh walaupun memang sebenarnya anak belum mengetahui makna yang sebenarnya. seperti yang diungkapkan oleh Syamsu Yusuf yang mengungkapkan bahwa perkembangan moral anaak banyak dipengaruhi oleh lingkungannya, hal ini menguatkan bahwa memang perkembangan moral anak memang perlu dibiasakan, pemberian contoh atau keteladanan dan konsisten dalam mendidiknya sehingga anak akan menerapkan nilai-nilai moral dengan benar (Yuningsih, 2014).

\section{SIMPULAN}

Berdasarkan hasil asesmen perkembangan yang dilakukan pada kelompok A di TKIT Al-Ikhlas Al-Ma'aruf sebanyak sepuluh anak diperoleh hasil 95\% anak sudah berkembang dengan baik sesuai dengan Standar Tingkat Pencapaian Perkembangan Anak (STPPA) dan dapat dikatakan tidak ada hambatana atau permasalahan dalam perkembangan NAM. Hal ini menunjukan bahwa perkembangan nilai agama dan moral melalui indikator capaian yang 
AWLADY: Jurnal Pendidikan Anak

Homepage: www.syekhnurjati.ac.id/jurnal/index.php/awlady

Email : pgrasyekhnurjati@gmail.com

P-ISSN: 2541-4658

E-ISSN: 2528-7427
Vol. 6, No. 2, September 2020

ditetapkan oleh peneliti menunjukan perkembangan NAM yang sangat baik. Namun sebaiknya guru dan orangtua sejatinya tidak puas dengan hasil capaian perkembangan anak. Guru perlu terus melakukan stimulasi lanjutan di dalam kelas, sehingga perkembangan anak khsusunya nilai agama dan moral terus berkembang sampai pada tahapan berkembang sangat baik. Tidak hanya peran guru, namun peran kolaborasi antara guru dan orang tua juga sangat penting, sehingga proses asesmen dalam semua aspek perkembangan dapat berjalan dengan baik.

\section{DAFTAR PUSTAKA}

Anggraini, W., \& Syafril, S. (2018). Pengembangan Nilai-Nilai Moral dan Agama pada Anak Usia Dini. Jurnal Pendidikan Anak Usia Dini, 3(1). https://doi.org/10.13140/RG.2.2.22657.10085

Erlina. (2018). Meningkatkan Kemampuan Kognitif Mengurutkan Bilangan 1-10 Melalui Media Pohon Hitung Anak Kelompok B Di TK Baptis Setia Bakti Kota Kediri. Jurnal Inovasi Pembelajaran, 3(2).

Hartati, S. (2017). Pengembangan Model Asesmen Perkembangan Anak Taman KanakKanak Di Dki Jakarta. Jurnal Pendidikan Usia Dini, 11(1), 19. https://doi.org/10.21009/jpud.111.02

Laila Maharani. (2014). Perkembangan Moral pada Anak. Jurnal Bimbingan Dan Konseling, 1(2), 104-109. https://doi.org/10.1371/journal.pone.0091987

Norlaila. (2015). Upaya Pengembangan Aspek Kognitif Dalam Aktivitas yang Bersifat Eksploratif dan Menyelidiki (Mencampur Warna) menggunakan model Example Non Examples di Kelompok B TK Tunas Muda Kec. Simpang Empat Kab.Banjar. JEA, $1(1), 66-95$.

Rahman, U. (2009). Karakteristik Perkembangan Anak Usia Dini. Lentera Pendidikan, 12(1), 46-57. https://doi.org/10.24252/lp.2009v12n1a4

Rasyid, H., Mansyur, \& Suratno. (2012). Asesmen Perkembangan Anak Usia Dini. Yogyakarta: Gama Media.

Retnaningrum, W. (2016). Peningkatan Perkembangan Kognitif Anak Usia Dini Melalui Media Bermain Memancing. Jurnal Pendidikan Dan Pemberdayaan Masyarakat, 3(2), 207. https://doi.org/10.21831/jppm.v3i2.11284

suyadi. (2016). Perencanaan dan Asesmen Perkembangan Pada Anak Usia Dini. Jurnal Ilmiah 
Homepage: www.syekhnurjati.ac.id/jurnal/index.php/awlady

Email : pgrasyekhnurjati@gmail.com

P-ISSN: 2541-4658

E-ISSN: 2528-7427

Tumbuh Kembang Anak Usia Dini, 1(1), 2502-3519.

Talango, S. R., \& Pratiwi, W. (2018). Asesmen Perkembangan Anak (Studi Kasus Asesmen Perkembangan Anak Usia Dini Usia 2 Tahun). Jurnal Manajemen Pendidikan Islam, $6(2)$.

Yuningsih. (2014). Menguatkan Kembali Pendidikan Keagamaan Dan Moral Anak Didik. $\operatorname{VIII}(2), 199-216$. 